\title{
Reforma del empleo público: Tótem y Tabú
}

\section{Francisco Longo *}

\section{Introducción}

La expectativa de una nueva reforma legal del empleo público ha vuelto a hacer su aparición en la escena administrativa. El acuerdo-marco suscrito entre la Administración del Estado y los sindicatos más representativos, en septiembre último, contempla la elaboración y negociación de un nuevo estatuto de la función pública, fijando incluso para ello previsiones de calendario.

No son pocos, en mi opinión, en nuestro mundo público, quienes comparten una visión totémica de dicha reforma legal, ya sea depositando en la misma expectativas desmesuradas, o convirtiéndola en el único o principal impulsor de una mejora sustancial del actual sistema de gestión pública de recursos humanos. No es éste un enfoque privativo de quienes se ocupan del empleo público. Años después de reiterar en todos los foros que no se cambia por decreto, la confianza en la reforma normativa como el principal instrumento para el impulso y desarrollo de las políticas públicas sigue formando parte de las señas de identidad de nuestra Administración.

En el campo que nos ocupa, esta contumaz percepción tiene algo de la fe del carbonero, si se piensa en el saldo de las reformas precedentes del estatuto funcionarial, causantes de un buen número de expectativas frustradas, según es hoy ampliamente reconocido.

Al mismo tiempo, al levantarse el telón de la reforma legal, irrumpen en el escenario los viejos tabúes de nuestro empleo público. Es la nuestra una época caracterizada por la aceleración de los cambios y el incremento de las incertidumbres, en especial en el mundo del trabajo ${ }^{1}$; por la necesidad de repensar la naturaleza, dimensión y especificidad de lo público; por la difuminación de fronteras seculares entre lo público y lo privado en la provisión de bienes y servicios; por la aparición dël binomio competitividad/flexibilidad en el discurso estratégico de las organizaciones. En tal contexto, la tentación de mantener la configuración del empleo público como un sistema cerrado en sí mismo, nutrido del discurso esencialista de la singularidad, amparado en una interpretación extensiva de los preceptos constitucionales, no es, a mi juicio, sino una respuesta defensiva a necesidades de estabilidad, seguridad y certeza que el entorno pone, cada vez más, en peligro.

El problema es que lo que la sociedad demanda de la Administración no es que se defienda del entorno, sino más bien que sea capaz de interpretarlo y adaptarse a él. El camino de la modernización de nuestro sistema público está hecho de respuestas renovadas, a la altura de los retos de los tiempos que nos ha tocado vivir. A reflexionar sobre esas respuestas, en lo que al empleo público se refiere, están dedicadas las líneas que siguen.

\section{LOS TABÚES DEL EMPLEO PÚBLICO}

Dice la Real Academia que tabú es la condición de personas, cosas o instituciones, que no es lícito censurar o mencionar. Algunas peculiaridades del marco actual del empleo público se corresponden con rasgos profundos de nuestra cultura administrativa, que rara vez son puestos en cuestión.

Se trata de modelos mentales profundamente arraigados en el inconsciente colectivo de nuestras Administraciones, cuya persistencia constituye, en mi opinión, el principal obstáculo a la producción de los cambios necesarios. 


\section{El miedo a la diferencia: la burocracia clónica}

Parafraseando el conocido dilema de Goethe, podría decirse que nuestra Administración ha preferido tradicionalmente la ineficacia al desorden. Lo peor de todo es que ha acostumbrado, además, a confundir el desorden con la diferencia.

La ordenación legal de nuestra función pública parece basada en la producción, en un laboratorio, de un modelo cerrado de regulación, concebido para ser posteriormente reproducido por clonación en los diferentes sectores y organizaciones de nuestro mundo administrativo.

Más de una vez me he preguntado cuál es el bien jurídico que se protege prescribiendo, por ejemplo, que toda organización pública deba forzosamente estructurar sus puestos de trabajo en precisamente treinta niveles, ni uno más ni uno menos, estableciendo una lista cerrada de conceptos retributivos, o prohibiendo, con carácter general, que en caso alguno pueda asignarse más de un complemento especifico a cada puesto de trabajo.

Esta concepción clónica de nuestro marco de empleo público entra, a mi juicio, en abierta contradicción con la realidad y evolución de nuestro sistema administrativo que, como consecuencia de la importante expansión de la actividad del Estado que caracteriza a nuestra época, ha sufrido una considerable diversificación. En la realidad administrativa de nuestros días encontramos actividad reguladora, prestadora y promotora; servicios que operan dentro y fuera del mercado; unidades que venden servicios y se autofinancian e incluso obtienen excedentes, y otras que se nutren sólo del déficit; órganos que realizan actividades repetitivas en medios estables, y otros que se ven obligados a innovar en entornos de extrema fluidez; actividades consolidadas y permanentes y programas incipientes o temporales; unidades autosuficientes y servicios que requieren complejas interacciones de diferentes organismos; trabajo rutinario o de baja especialización, junto a sofisticadas exigencias de la más alta cualificación profesional.... Tiene sentido un marco normador de la relación de empleo que pretenda regular en detalle y con carácter uniforme tamaña diversidad? ${ }^{2}$.

Pero, además, tal orientación es en mi opinión incompatible con la realidad de nuestro Estado compuesto. Porque si el marco jurídico del empleo público debiera contemplar la diversidad apuntada en la misma esfera de la Administración estatal, con mayor razón habría de ser respetuoso con la diferencia a la hora de ordenar la función pública de Comunidades Autónomas y poderes locales. La exportación de instrumentos y técnicas pensados, con acierto o sin él, para la Administración central, caracteriza a menudo la producción normativa en este campo.

Un ejemplo relativamente reciente: La compleja regulación diseñada por la Ley $22 / 93$, para la reasignación de efectivos excedentes, en el marco de los planes de empleo, tiene su razón de ser en el enorme tamaño y diversificación organizativa y territorial de una Administración central concebida, a estos efectos, como unidad de gestión del proceso. A nadie parece habérsele ocurrido pensar, antes de establecer la exportación de la norma a todo nuestro universo administrativo, en la existencia de miles de instituciones locales para las que la misma, además de virtualmente inaplicable, resulta un tanto estrambótica.

\section{El proyecto antidiscrecional como esquema dominante}

La existencia de una Administración profesional que sirva con independencia, objetividad e imparcialidad los intereses públicos forma parte de las señas de identidad del moderno Estado de Derecho. También está en la ésencia del mismo la necesidad de que tal aparato administrativo responda con eficacia al cumplimiento de sus finalidades, aplicando políticas diseñadas por gobernantes democráticamente elegidos.

La articulación entre política y administración exige el adecuado equilibrio entre valores constitucionalmente protegidos: los que limitando la discrecionalidad del poder político tienden a preservar la profesionalidad de la Administración, y aquéllos que se dirigen a garantizar la eficacia con que ésta debe servir los intereses generales y producir los servicios públicos, de acuerdo con las orientaciones del gobierno legitimamente constituído.

En nuestro modelo de empleo público, tales valores se hallan, en mi opinión, frecuentemente desplazados del punto adecuado de equilibrio. Probablemente como consecuencia de lo que algunos han llamado ${ }^{3}$ el proyecto antidiscrecional, que en buena parte sigue caracterizando a nuestro Derecho público, el estatuto funcionarial presenta un sesgo marcadamente garantista, orientado a la protección del servidor público frente a los abusos del poder político, y ello se produce, en ocasiones, en detrimento de la eficacia de los procesos de gestión de recursos humanos (en adelante, GRH).

Tomemos como ejemplo la regulación del sistema ordinario de provisión de puestos de trabajo. Sin duda, un procedimiento como el actual, basado en la acreditación de méritos formales, documentalmente comprobables, parece de entrada limitar la eventual arbitrariedad en la adscripción; desde luego, presenta una apariencia de mayor rigor que la evaluación del rendimiento anterior del aspirante o la utilización de la entrevista de selección, técnicas más susceptibles de carga subjetiva. El problema es que, en general, el primer tipo de método no garantiza casi nunca la idoneidad del aspirante y su consiguiente adecuación al puesto. No parece un problema pequeño, en términos de eficacia del proceso.

El sesgo garantista que he atribuído a buena parte de nuestro marco legal del empleo público se manifiesta en una hiperregulación de garantías formales. Son los procedimientos, más que el fondo de los procesos, los que constituyen el objeto preferente de regulación.

Me explicaré con un ejemplo: el legislador norteamericano ha intentado garantizar la vigencia efectiva del sistema de mérito en la Administración federal mediante la creación de una instancia, el 
Merit System Protection Board ${ }^{4}$ que, configurada como un órgano independiente y legitimada por ello y por una alta tecnificación y profesionalidad de sus integrantes, vela por la limpieza y transparencia de procesos cuya regulación procedimental es bastante escueta, y los revisa en caso necesario, para evitar arbitrariedades o discriminaciones. En nuestra tradición administrativa, tales instrumentos son desconocidos. En su lugar, nuestra regulación es rica en controles previos, requisitos documentales, plazos, publicaciones, certificaciones y otras prescripciones de trámite.

Mi punto de vista es que esta orientación complica y vuelve rígida la gestión, sin ofrecer muchas veces verdaderas garantías sustantivas de protección de los valores cuya vigencia se persigue. Todo gestor público podría citar casos de procesos de personal teledirigidos, pero amparados, eso sí, por el cumplimiento de todas las garantías formales legalmente exigidas.

Un efecto directamente imputable a esta orientación es la creciente judicialización de la función de personal en nuestras Administraciones. Una parte apreciable de las energías de los órganos administrativos especializados en esta área se dedica a velar por la corrección formal de los procesos, buscar resquicios en el bosque de regulaciones, analizar la cascada jurisprudencial y evitar pronunciamientos jurisdiccionales contrarios.

\section{El enemigo exterior: lo privado como disvalor}

En el primer número de GAPP, BARZELAY ${ }^{5}$ señalaba cómo la metáfora Government is a Business "...fue especialmente bien recibida (en los Estados Unidos del Presidente Woodrow Wilson) por aquéllos que aborrecían el spoils system, o que no podian soportar hechos como funcionarios incompetentes, favoritismo en las contrataciones, laxitud en los controles financieros o mecanismos muy débiles de control de los organismos administrativos". Pues bien, para expresar tales valores nuestra cultura administrativa acostumbra a utilizar justamente la metáfora opuesta: La Administración no es una empresa.

Además de provocar la sonrisa, la paradoja mueve a la reflexión. Lo empresarial, que en el primer caso es vivido como sinónimo de rigor, responsabilidad, control, profesionalidad, es satanizado en nuestro entorno como equivalente, parece, a lo contrario. La concepción de lo público como un universo regido por valores propios, sustancialmente distintos, y aun opuestos, de los que rigen la actividad de las organizaciones privadas, constituye un reflejo cultural profundamente arraigado en nuestra Administración y su entorno próximo. Quienes hemos defendido que el management público no es sólo un repertorio de técnicas de gestión, sino también un discurso portador de valores necesarios para la renovación de nuestras organizaciones públicas, hemos tenido alguna vez la sensación de ser contemplados desde el escepticismo del convencido de que extra ecclesiam nulla salus.

En el campo del empleo público, este reflejo se ha traducido en un considerable alejamiento del marco regulador del mismo, con respecto del que rige el trabajo por cuenta ajena en nuestra sociedad. No se trata sólo de que se hayan incorporado regulaciones específicas derivadas de la necesidad de proteger determinados valores propios de la relación pública de empleo, sino de que ésta ha sido objeto de una construcción jurídica que se ha afirmado fundada sobre presupuestos esencialmente distintos. El origen legal, no convencional, de la relación, ha servido habitualmente de base a esta radical diferenciación.

Y sin embargo, como ha sabido ver CASSESE ${ }^{6}$, en un contexto no tan diferente del nuestro, "...no puede decirse que la relación de empleo público es distinta de la del privado porque la regulación de la primera no está a disponibilidad de las partes, mientras que sí lo está la segunda. En ambos campos existe una regulación legal, aunque con distinta extensión, motivada por la protección del trabajo subordinado, motivación que es tan intensa en el área pública como en la privada y que, por tanto, ha producido resultados que no son diferentes".

Sea como fuere, lo cierto es que en nuestro marco estatutario la protección del trabajo subordinado, mencionada por el autor italiano, va tan lejos, y afecta a tantos elementos de la relación, que se configura no sólo como algo lejano de la sociedad, sino incluso difícil de ser percibido sólo en clave de interés general. La imagen del funcionario como detentador de privilegios, tan arraigada en la cultura popular, tiene algo que ver con la opacidad que para millones de trabajadores por cuenta ajena de nuestro país presenta un régimen de empleo autoalimentado de tal singularidad.

Lo más curioso es que esta huida de lo privado, este alejamiento del régimen común del trabajo asalariado, no afecta al conjunto del empleo público. Después de décadas de construcción de un modelo basado en la singularidad esencial de éste, la relación laboral no ha dejado de estar presente en el ámbito público, con una persistencia que pone, a mi juicio, en cuestión el discurso esencialista ${ }^{7}$. En nuestros días, esta presencia se produce en dos esferas diferenciables a fines sistemáticos:

De un lado, la relación de Derecho laboral aparece como régimen de empleo de elección potestativa para ciertos puestos de trabajo. Cabría suponer que se trata de aquéllos -si es que existen- cuyas funciones no exigen una especial protección de los valores (imparcialidad, independencia, objetividad...) propios del régimen público. El análisis de nuestro Derecho positivo dejaría perplejo a quien pretendiera confirmar tal presunción. Quien examine el precepto de la Ley 30/84, que delimita tales puestos en la esfera de la Administración estatal, podrá comprobar que la apertura al empleo laboral se opera sin que resulte evidente el criterio utilizado, y en forma tal que levanta ciertas sospechas de arbitrismo e incluso de influencia corporativa ${ }^{8}$.

Por otro lado, el empleo laboral aparece asociado a operaciones de descentralización funcional mediante la creación de entidades autónomas, en el marco de lo que tantos autores han llamado procesos de buida del régimen público. En alguno de estos casos, da la impresión de que el cambio del régimen de empleo del personal ha sido el primer objetivo perseguido, en busca de una mayor flexibilidad. Tampoco aquí la diferencia se relaciona con cambios en la naturaleza de la función, que per- 
manece inmutable. ¿Qué se ha hecho, en tales supuestos, de los valores supuestamente garantizados por el régimen estatutario?

Esta dualidad de regímenes, asentada sobre bases conceptuales tan frágiles, ha conducido a nuestras Administraciones, en los últimos años, a movimientos pendulares que han complicado, a veces extraordinariamente, la gestión, y han creado perjuicios considerables al personal afectado ${ }^{9}$. El espectáculo de la llamada funcionarización, por citar el proceso de mayor calado, iniciado hace siete años en nuestra Administración estatal, y hoy todavía abierto, resulta desde luego poco edificante ${ }^{10}$.

\section{El olvido de la dirección}

Si lo empresarial ha sido un disvalor para nuestra cultura administrativa, no es incoherente que el marco jurídico del empleo público parezca desconocer, de hecho, la función directiva.

En el modelo burocrático de Administración, la delimitación básica de roles de los sujetos de la acción pública ha girado alrededor de la dicotomía weberiana que distinguía entre funcionarios politicos y funcionarios profesionales, correspondiendo a los primeros la formulación de las políticas, y a los segundos la ejecución de las mismas. Tal formulación se ha visto seriamente afectada por la evolución del Estado y su papel, que ha incrementado extraordinariamente la complejidad de las funciones de dirección y gestión en los sistemas públicos. Esta complejidad ha desajustado el engranaje entre política y administración, tal como había sido construído por la burocracia tradicional.

Una función trascendente comienza a ser exigida por el marco de complejidad apuntado, entre el momento de la formulación de las políticas y el de su ejecución y desarrollo: la dirección de los procesos a través de los que se preparan y ponen en práctica las políticas y se producen los servicios públicos. En otras palabras, una función directiva o gerencial hace su irrupción en los sistemas públicos, y lo hace en forma de necesidad ampliamente sentida por los sujetos, activos y pasivos, de la acción administrativa.

La captura de las responsabilidades directivas por la función pública ordinaria ha sido un hecho frecuente. El modelo británico ha sido considerado (sobre todo antes de las grandes reformas de la última década) como el caso más representativo. De hecho, esta versión ha sido teorizada a menudo como el paradigma de la profesionalización de la Administración. En el entorno español, son muchas las voces que se han alzado en tal sentido, para reclamar, en especial, la prolongación de la carrera administrativa de los funcionarios estatales hasta el nivel de director general.

Sin embargo, la realidad ha puesto de manifiesto significativas limitaciones y serios inconvenientes de este enfoque, derivados de la incapacidad de la función pública tradicional para desarrollar en su interior una función gerencial y situarla, con acierto y fluidez, en los puestos de dirección requeridos.

Esta incapacidad deriva, de una parte, de la configuración misma de la función pública, integrada por un conjunto de sub- culturas técnicas y profesionales, cuya heterogeneidad ha crecido con la expansión de los ámbitos de actuación del Estado, y que en el caso español se hace claramente reconocible en el sistema de cuerpos, sin que en tal mosaico sea fácil hallar elementos que apunten al nacimiento y desarrollo de una cultura directiva.

De otro lado, las limitaciones mencionadas obedecen a la rigidez propia del régimen estatutario, y a las dificultades que del mismo se desprenden para el acceso a los puestos de responsabilidad de los perfiles directivos necesarios, así como para el estímulo posterior del ejercicio de responsabilidades gerenciales en condiciones semejantes a las que son propias de la función directiva o ejecutiva en otras organizaciones y entornos.

Yendo al marco estatutario español, resulta difícil pensar en el desarrollo de una función directiva, en un contexto nutrido de ingredientes como: la estructura de grupos de titulación y niveles; el régimen de elaboración y aprobación de las relaciones de puestos de trabajo; una provisión de puestos limitada a funcionarios de los niveles adecuados; unos mecanismos de provisión, o inservibles a los efectos pretendidos (el concurso, lastrado por el peso de la meritocracia formal), o carentes de una imagen de legitimidad (la libre designación, puesta al servicio de la confianza política o puramente personal), ante el nulo desarrollo interno de sistemas fiables de apreciación de la idoneidad; un régimen de retribución cuya complejidad corre pareja a su rigidez; y unos mecanismos costosos, y ampliamente desprestigiados en la práctica, de recompensa del rendimiento individual ${ }^{11}$

\section{La sacralización de la movilidad como derecho subjetivo}

En un diseño correcto de GRH, la movilidad del personal se asienta -como tantas otras áreas de aquélla- sobre un juego de equilibrios. Este diseño tratará de compatibilizar las necesidades y estrategias de la organización, conducentes a un óptimo aprovechamiento de su capital bumano, con las aspiraciones e intereses del personal, orientados a la realización de la tarea en las condiciones más gratificantes y satisfactorias, desde el punto de vista individual.

En el empleo público de nuestro país, la regulación de la movilidad convierte a ésta en algo muy próximo a un derecho subjetivo individual del funcionario, lo que desequilibra fuertemente el diseño aludido, en detrimento de la lógica de la gestión.

Un ejemplo ilustrará lo anterior. Altos responsables de personal del Instituto Nacional de la Seguridad Social (INSS) me hablaban hace unos meses del concurso de provisión de puestos celebrado el año pasado. El propósito del INSS era cubrir 1067 vacantes en su estructura de puestos, que integra a unos 12.500 funcionarios.

El concurso fue gestionado por el Ministerio de Trabajo y Seguridad Social; en el que el Instituto está integrado como 
organismo autónomo, y se hizo extensivo a la provisión de vacantes en diferentes organismos que integran al personal de la antigua Seguridad Social, por lo que incluyó, junto al INSS, a la Tesorería General, el Instituto Social de la Marina y la Gerencia de Informática, e incluso a organismos que ya no pertenecen a dicho Ministerio, como el INSALUD (Mo de Sanidad) y el INSERSO (Mo de Asuntos Sociales).

Participaron en el concurso cerca de 4.500 funcionarios del INSS, lo que supuso una rotación superior a la tercera parte de la plantilla. El resultado, en términos numéricos, en lo que al INSS respecta, es que las vacantes iniciales se transformaron en 1068: justamente una más que antes de iniciarse el proceso. Con todo, lo peor, para los responsables del Instituto, fue que la distribución resultante creó graves desequilibrios dotacionales entre las direcciones provinciales, muy superiores a los que existían previamente. Cabe añadir que a los enormes costes de gestión del proceso, hay que sumar los de la elevada rotación, que se tradujo, entre otros efectos, en una ingente inversión en formación para adaptar funcionalmente a las personas que se desplazaron.

Es perfectamente explicable que se produzcan estos efectos cuando la escala de intervención se diseña, no en función de las necesidades organizativas, sino de la suma de expectativas e intereses individuales preexistentes, configurados como derechos subjetivos. El ejemplo es también expresivo de los problemas que origina una concepción hipercentralizada de la gestión de personal, a la que luego se hará referencia.

La existencia de esta disfunción complica la misma corrección de sus efectos. La Ley 22/93, ya citada, cuya finalidad principal es flexibilizar los procesos de reasignación de efectivos en el sistema público, es tributaria de esta concepción de la movilidad cuando configura, como ámbito para gestionar tal reasignación, en los supuestos de supresión de puestos de trabajo, la totalidad de la Administración estatal, central y periférica, y sus organismos autónomos. Es fácil vislumbrar la enorme dificultad que implica la intervención en una macroescala de tales dimensiones.

Algunas voces han relacionado este problema con la técnica jurídica, propia de nuestro Derecho público, consistente en la atribución, al Estado y las Administraciones territoriales, de personalidad jurídica única. Tengo mis dudas de que se halle aquí la clave del problema, por lo que me limitaré a dejar la referencia apuntada. Sí estoy convencido de que urge una revisión en profundidad de la noción de movilidad configurada por el marco estatutario vigente, cuyos efectos negativos para la gestión pública no acierto a identificar como la consecuencia inevitable de la protección de bienes jurídicos de interés general.

\section{El empleo vitalicio como sinónimo de estabilidad}

En sesiones de formación con directivos públicos suelo plantear la siguiente pregunta: "Qué es, a vuestro juicio, para un ciudadano de nuestro país, un empleo estable?". La primera res- puesta brota de inmediato: "Un contrato de trabajo indefinido". Basta un breve silencio para que alguien complemente dicha respuesta con otra: "Una empresa sólida". En efecto, creo que la combinación de una relación de trabajo no sujeta a plazo, y jurídicamente protegida, y de un empleador solvente, no amenazado en el corto plazo por la crisis, constituiría, para un elevado porcentaje de nuestros conciudadanos, el arquetipo de la estabilidad en el empleo (y aspiración insatisfecha de muchos, dicho sea de paso, en los días que vivimos).

Cuando a continuación pido al grupo una respuesta sobre qué se debe considerar estabilidad en el empleo público, el debate está servido. Desde luego, los dos componentes citados se dan, en este ámbito, por supuestos: Salvo una porción, insignificante a los fines de nuestro análisis, de trabajo estacional o temporal, la relación de empleo público es indefinida; por otra parte, ningún empleador goza de la solidez y permanencia de las instituciones públicas.

Sin embargo, la concepción común de la estabilidad en el empleo, en el ámbito público, añade al concepto un plus considerable, que se identifica con la noción de inamovilidad. Tal noción, que lleva a sus últimas consecuencias la protección del trabajo administrativo subordinado, frente a la eventual arbitrariedad del poder político, se usa a menudo como un eufemismo tras el cual se perfila la garantía de empleo de por vida para el personal público.

Nos hallamos sin duda ante el núcleo duro de la configuración normativa del empleo público como becho diferencial. No parece necesario gastar mucho espacio en describir cómo dicha configuración tiende a modular las Administraciones como sistemas cerrados, impenetrables por los cambios del entorno; o hasta qué punto tiende a petrificar la acción pública, sustrayéndole la flexibilidad necesaria para revisar estrategias, rediseñar prioridades, remodelar servicios, hacer frente a la obsolescencia de sectores 0 actividades, y adaptarse a una demanda social cambiante.

Quizá por ello, tal concepción de la estabilidad no sobrevive sin sobresaltos. Alguna iniciativa legislativa reciente (la repetida Ley 22/93) ha pretendido enfrentar este estado de cosas mediante la reformulación de una institución, la llamada excedencia for$z o s a$, nacida, en su formato actual, para flexibilizar el sistema hasta el límite que es posible hacerlo sin cuestionar la concepción del empleo vitalicio como derecho adquirido, por utilizar el argot funcionarial. El problema es que, en mi opinión, tal vía media pone descarnadamente al descubierto un tratamiento del desempleo funcionarial abiertamente privilegiado y discriminatorio, respecto del que resulta aplicable a los demás sectores de nuestra sociedad.

He oído aducir a veces, como justificación de tales diferencias de configuración legal, las dificultades que existen para determinar, sobre bases objetivas, la existencia de empleo redundante en las Administraciones y, en consecuencia, para identificar las necesidades de amortización de puestos de trabajo. Ciertamente, la inaplicabilidad de la lógica del mercado introduce aquí indudables problemas de objetivación y hasta de legitimación subjetiva, cuya solución no es nada fácil. 
Pero repárese en que si enfrentamos tales problemas -a lo que, en mi opinión, debiera dedicarse una buena parte del esfuerzo reformador- estaremos trasladando el eje de la cuestión. Habremos salido del círculo cerrado de la inamovilidad como garantía de valores no siempre identificables, para preguntarnos en qué casos, con qué requisitos, mediante qué aparato de garantías, con la participación de qué sujetos, a través de qué instituciones, mediante el uso de qué instrumentos y técnicas habría de determinarse, en forma objetiva y satisfactoria, la redundancia u obsolescencia de puestos de trabajo en el ámbito público, y la consiguiente extinción de las relaciones de empleo afectadas.

\section{LA REFORMA DEL ESTATUTO: MITO O INSTRUMENTO}

Enfrentar los tabúes del empleo público y corregir sus efectos nocivos para la gestión de nuestras Administraciones son propósitos que exigen la reforma legal. Cabe preguntarse, sin embargo, hasta qué punto las reformas jurídicas son capaces de resolver por sí mismas los problemas que aquejan a la GRH en nuestro sistema público.

Para ello, parece imprescindible apuntar -aunque sea con la brevedad y esquematismo que impone el alcance de este artículo- algunos elementos de diagnóstico sobre tales patologías.

\section{Siete pecados capitales del modelo actual de GRH}

Me atrevo a suponer -y para ello me baso tanto en mi propia experiencia como directivo público, como en opiniones publicadas, foros de debate en los que vengo participando desde hace años, y muy especialmente en el contacto con gestores públicos en cursos de formación de directivos- que podría alcanzarse un alto grado de consenso, entre gestores de diferentes Administraciones, sectores y niveles de responsabilidad, en torno a las siguientes proposiciones, cuyo orden no expresa prioridad:

1. El modelo de GRH vigente en las Administraciones españolas no es capaz de producir competencias directivas a la altura de las necesidades del sistema público, ni de garantizar que los perfiles directivos que se producen sean correctamente ubicados y aprovechados. Este problema afecta fundamentalmente al funcionamiento de los subsistemas de reclutamiento, selección, provisión de puestos de trabajo, evaluación y formación.

2. Una excesiva centralización de las decisiones en materia de personal obstaculiza con frecuencia una gestión eficaz y eficiente de los servicios públicos. La escala en que se manejan determinados procesos relativos a los recursos humanos (diseño de puestos, selección, provisión...) aleja los problemas de los centros de decisión, lo que dificulta la producción de las respuestas adecuadas.
3. Los gestores de los servicios públicos y, en general, los responsables de unidades administrativas se desentienden a menudo de la asunción de responsabilidades de GRH, en relación con el personal que tienen adscrito, ya sea considerando que tales responsabilidades no forman parte de los cometidos que tienen asignados, o simplemente rehuyendo el conflicto que su ejercicio puede comportar.

4. Funcionan mal, en general, los mecanismos de planificación, racionalización y reasignación de recursos humanos. Se halla extendida en muchas Administraciones la convicción de que coexisten sectores infradotados, con bolsas excedentarias de personal, cuya detección y tratamiento plantean serias dificultades. Ello favorece el mantenimiento de una lógica incremental en la cobertura de necesidades de personal, y dificulta las políticas de reducción de costes.

5. Existen disfunciones significativas en el diseño de carreras, especialmente en las áreas y servicios, con creciente peso numérico y cualitativo en el sistema público, de componente básicamente técnico-profesional. Los mecanismos de promoción siguen articulando carreras jerárquicas de tipo burocrático, que no dan respuesta a las necesidades de dichos sectores ni a las expectativas de desarrollo profesional del personal afectado.

6. Hay una separación prácticamente absoluta entre el desempeño en el puesto y el funcionamiento de los subsistemas de recompensa (retribución y promoción). Dicha separación es también frecuentemente constatable en lo que respecta a algunas políticas de desarrollo, como la formación.

7. Algunos marcos procedimentales (provisión de puestos, remoción, corrección disciplinaria) son de tal rigidez que complican considerablemente la gestión en dichas áreas. Ello favorece la inacción en ciertos campos (remoción, sanción), el uso de mecanismos de mera cobertura formal, incluso en fraude de ley (concursos, habilitaciones...) y, desde luego, una creciente judicialización del empleo público.

Los males del sistema no se agotan, con seguridad, en el enunciado de estas siete proposiciones. Por otro lado, el peso e importancia de las disfunciones apuntadas no es, desde luego, el mismo en las diferentes organizaciones públicas. Creo, sin embargo, que, tomados en conjunto, constituyen el núcleo básico de problemas que afronta hoy la GRH en nuestro entorno público. Dicho de otro modo, la corrección de estas patologías daría lugar a una mejora muy significativa de la situación vivida hoy, en este campo, por la práctica totalidad de nuestras Administraciones ${ }^{12}$.

\section{Las raíces de los problemas}

Una de las primeras conclusiones que pueden desprenderse de este rápido examen de las disfunciones del sistema público de GRH es que las mismas aparecen situadas, en buena parte, en áreas causales distintas del marco jurídico regulador del empleo público. Parece imprescindible identificar dichas áreas, si se pretende que las estrategias de reforma se enfrenten a las verdaderas raíces de los problemas. 
El primero de los campos en que germinan algunas de las patologías enunciadas es el del diseño organizativo. Algunos de los principales desajustes de la GRH en el ámbito público derivan de un diseño organizativo inadecuado, traducible en una excesiva centralización de la función de personal, que tiende a uniformizar el tratamiento de problemas heterogéneos, a utilizar un hipertrofiado abanico de controles primarios sobre el procedimiento, a sustraer autonomía a los gestores y, por ende, a desresponsabilizar a éstos de la gestión de su personal. Sólo en una porción limitada, poco relevante a mi juicio, tales problemas de diseño derivan de constricciones de orden jurídico.

Se trata, desde luego, de un problema especialmente acusado en la Administración del Estado, pero con el que tropezamos en los demás niveles de Administración, en directa relación con el tamaño y heterogeneidad de las organizaciones públicas.

La actuación sobre tal diseño organizativo, y la consiguiente descentralización del proceso decisor y el apoderamiento de los gestores de línea se configuran como una condición de partida para la efectividad de otras innovaciones, entre otras las que puedan derivarse de modificaciones del marco normativo. En otro lugar ${ }^{13}$, he mantenido que tales transformaciones preceden, en nuestro entorno, a las demás reformas de la GRH, como un prerrequisito sin el cual difícilmente podrán ser liberadas las fuerzas que apuntan al cambio; un cambio que será policéntrico o no será. De hecho, se trata de un eje crucial de las grandes reformas que, durante la última década, han transformado en profundidad los sistemas públicos de bastantes países del mundo desarrollado ${ }^{14}$.

La segunda de las áreas causales identificables puede ser enunciada como la falta de claridad en la definición de estrategias 0 , si se prefiere, como la ausencia de políticas de recursos humanos. Si las organizaciones públicas no establecen objetivos, no evalúan resultados, diseñan mal las carreras profesionales o no elaboran buenos planes de formación, por tomar algunos ejemplos significativos, no parece que ello sea imputable a constricciones externas relevantes, sino más bien a un déficit de orientación estratégica en lo que respecta a las políticas de GRH. A falta de tales políticas, la GRH se transforma en administración de personal, actividad puramente aplicativa que se limita a reproducir lo existente.

Se trata de un déficit que cabe situar en los sistemas de dirección de las instituciones, al que difícilmente cabe hacer frente con medidas de orden normativo. Más bien serán necesarios planes capaces de introducir la GRH en el discurso estratégico de las organizaciones públicas.

En ocasiones, y en forma más o menos asociada al déficit de estrategias, nos encontramos -y ésta sería la tercera de las áreas causales detectables- con un déficit de capacidad institucional para desarrollar las políticas de recursos humanos, en especial las que implican innovación. Me refiero aquí a carencias directivas o técnicas en los sistemas de gestión, a problemas organizativos, de poder, de cultura, clima, consenso, en el interior de las organizaciones. A veces, la claridad en la definición de políticas no será suficiente para resolver los problemas indi- cados, si no se dispone de los instrumentos y las oportunidades para hacerlas operativas y eficaces.

Resulta difícil a veces delimitar cuándo un problema tiene su origen en esta clase de déficit o en los aludidos anteriormente. En cualquier caso, la definición y desarrollo de estrategias de fortalecimiento institucional, más que las reformas legales, serán el instrumento adecuado para combatir este tipo de carencias.

Desde luego, y sin perjuicio de lo anterior, el marco estatutario se evidencia como una de las áreas causales relacionadas con patologías del empleo público en nuestro país. Importa, sin embargo, señalar que la norma es sólo una fuente más de disfunciones, y que algunos de los principales problemas del empleo público se sitúan en otros campos, por lo que las reformas y estrategias adecuadas para superarlos se orientan prioritariamente en otras direcciones.

El tótem de la reforma del estatuto funcionarial debe ceder el paso a una visión más modesta, en la que las transformaciones del marco jurídico asumen un valor instrumental, de acompañamiento de reformas estructurales y estrategias de cambio, sin las cuales cualquier reforma legal sería, una vez más, una expectativa frustrada.

\section{¿QUÉ CLASE DE REFORMA LEGAL?}

Desde esta perspectiva, que pretende relativizar y enmarcar el alcance de las reformas legales en la corrección de las disfunciones de nuestro sistema público de GRH, parece posible aventurar algunas líneas de transformación del marco estatutario vigente, en sintonía con las reflexiones anteriores. Lo que sigue es un conjunto de ideas que pretenden sintetizar una posición respecto de los contenidos y método de dicha reforma, con un carácter de planteamiento inicial, pendiente, en no pocos aspectos, de desarrollo.

\section{Un nuevo estatuto}

Frente a la posición extrema de quienes han defendido una laboralización de nuestro régimen de empleo público, entendida como la directa aplicación de las normas que regulan, con carácter general, el trabajo por cuenta ajena en nuestra sociedad, es preciso mantener la necesidad de un marco de empleo específico del ámbito público, que garantice los principios y valores que le son propios.

La doctrina del Tribunal Constitucional establece categóricamente la necesidad de una regulación específica, de rango legal, de la relación de empleo público. Por lo que hace al ámbito de dicho marco normador, que la Constitución no precisa, el Alto Tribunal lo considera extensivo a la adquisición y pérdida del empleo, la promoción en la carrera, los derechos y deberes, la responsabilidad, las situaciones, el régimen disciplinario, la creación de cuerpos y escalas y la provisión de puestos de trabajo ${ }^{15}$. 
Lo que la doctrina constitucional no resuelve es cuál deba ser el contenido material de ese marco estatutario, y en qué medida el mismo deba resultar más o menos próximo o divergente del que regula con carácter general el trabajo por cuenta ajena. La determinación de tales contenidos corresponde, con el obligado respeto de los principios constitucionalmente protegidos, al legislador ordinario.

Desde mi punto de vista, la configuración de un nuevo estatuto debiera asumir tres orientaciones básicas:

* Debe ser un estatuto único: Sea cual fuere la posición que se mantenga, acerca de los principios y valores que la regulación específica del empleo público está llamada a garantizar ${ }^{16}$, resulta difícil de asumir que tal garantía no deba afectar, en general, a las diferentes parcelas de la acción pública, y al conjunto de servidores de la Administración.

Desde esta perspectiva, carece de sentido la subsistencia, en nuestras instituciones, de dos grupos de empleados, funcionarios y laborales, sujetos a regulaciones muy dispares, cuando menos en origen, cuya delimitación plantea, como vimos, serias dificultades. El resultado es una realidad de difícil manejo y una serie de problemas añadidos a la gestión del personal público, sin que de tal dualidad se desprendan beneficios apreciables.

* Debe ser un estatuto de minimos: La regulación básica del empleo público debe ser compatible con una concepción descentralizada de la GRH, a la que antes se hizo referencia. En particular, las distintas Administraciones territoriales deben contar con capacidad suficiente para ordenar su empleo y gestionar su personal con la flexibilidad necesaria. Para ello, debe huirse del criterio claramente abusivo de lo que hoy se considera bases del régimen estatutario, cuya prolijidad se impone como un corsé al conjunto de poderes públicos, desde una lógica centralista y uniformadora.

De otro lado, esta orientación es también un requisito para abordar la pluralidad y heterogeneidad de situaciones que la GRH enfrenta en el ámbito público. El estatuto debe configurarse como un estricto marco básico, contraerse a los rasgos necesariamente comunes del modelo, y permitir la existencia de regulaciones de desarrollo adaptadas a las necesidades y exigencias de los diferentes sectores de la acción pública.

* Debe ser un estatuto orientado a la flexibilidad: El término flexibilidad sintetiza, para la OCDE ${ }^{17}$, las orientaciones seguidas para la modernización de la GRH en los sistemas públicos del mundo desarrollado. Son orientaciones que se despliegan tanto en el plano de las políticas de planificación, racionalización y dimensionamiento de las dotaciones, como en el de las innovaciones en materia de remuneración, carrera, evaluación del rendimiento o formación, y tienden a permeabilizar las organizaciones públicas a las exigencias plurales y cambiantes del entorno.

En particular, el nuevo estatuto del empleo público debe facilitar, y no obstaculizar, el ejercicio de la función directiva, suministrando al gestor el margen preciso para dirigir recursos humanos en forma coherente con las estrategias de la organización, lo que exigirá la revisión de una parte del abanico de garantías for- males y constricciones procedimentales que, como se dijo, han ido depositándose, por acumulación, en la norma vigente.

\section{Un nuevo método para abordar la reforma legal}

A la hora de abordar la elaboración de un marco estatutario de las características apuntadas, podemos utilizar dos aproximaciones de signo opuesto: la primera consistiría en tomar como base la norma existente (básicamente, la Ley 30/84, pero también un conjunto de regulaciones vigentes considerablemente dispersas) y someterla a una revisión en profundidad, con arreglo a los criterios indicados; la segunda partiría de la legislación reguladora de la relación ordinaria de empleo (Estatuto de los Trabajadores y normas complementarias), e introduciría sobre esa base las especialidades y singularidades estrictamente necesarias para garantizar la operatividad de los principios y valores que distinguen al empleo público.

En mi opinión, debiera optarse resueltamente por la segunda de las opciones señaladas, por las siguientes razones:

En primer lugar, porque dicho enfoque traduce una orientación hacia la aproximación de la Administración y la sociedad, en un escenario, el del empleo, que constituye un referente de singular relevancia en nuestra época. Cuando la sociedad en su conjunto vive la crisis del empleo como una de sus principales preocupaciones, el empleo público no puede configurarse como una realidad alejada e ininteligible, vertebrada en base a sus propias instituciones y códigos, y regulada en tal forma que es frecuentemente visualizada desde fuera como un privilegio.

En segundo lugar, porque cuando la frontera entre lo público y lo privado ha perdido buena parte de sus contornos tradicionales, y la acción pública tiende a adoptar una pluralidad de formas diversas, la proximidad y mutua inteligibilidad de los marcos de empleo favorece la comunicación entre organizaciones llamadas a relacionarse y cooperar de maneras nuevas y diferentes, $y$ en sentido creciente.

Por último, y sobre todo, porque dicha aproximación es la que mejor garantiza que cada singularidad o especialidad del empleo público, que cada derogación específica del régimen del empleo común, queden adecuadamente valoradas y justificadas. Si el punto de partida es el marco del empleo ordinario, la norma reguladora del trabajo por cuenta ajena de los ciudadanos españoles, será necesario que cada una de esas derogaciones aporte valor, esto es, se fundamente en la necesidad de proteger bienes jurídicos que deberán quedar identificados y ser objeto de específica ponderación.

Dicho de otro modo, tal aproximación es la que mejor impide que se produzca esa amplia zona de tangencia que caracteriza al sistema actual, en la que la garantía de principios y valores de interés general tiende a confundirse con la defensa de intereses grupales o corporativos de los funcionarios. 


\section{Pautas singulares del régimen público de empleo}

Sin pretensión de exhaustividad, creo necesario apuntar, en la parte final de esta reflexión, algunas de las áreas de regulación en las que un futuro estatuto, elaborado con la orientación indicada, habría de incorporar singularidades propias del régimen público de empleo.

* La regulación del acceso al ejercicio de funciones públicas deberá garantizar la operatividad de los principios constitucionales de igualdad, mérito y capacidad. Es ésta una obligada especialidad del régimen público de empleo que constituye, a mi entender, su principal rasgo distintivo.

El mandato constitucional protege aquí dos órdenes de valores: de una parte, el derecho de los ciudadanos a optar al empleo público en condiciones de igualdad y no discriminación; de otra, la existencia de una Administración profesional cuyos servidores poseen y acreditan la idoneidad necesaria para el ejercicio, retribuído con cargo al erario público, de las funciones correspondientes.

Tal exigencia constitucional no obliga, en mi opinión, al mantenimiento del sistema -vigente en la Administración centralde acceso por cuerpos, ni a la separación entre los sistemas de acceso y provisión de puestos que caracteriza el actual modelo dual (de carrera y de empleo) de función pública.

Por el contrario, estoy convencido de que la garantía de los principios enunciados es perfectamente compatible con una regulación escueta y flexible, que se apoye mucho más en la intervención de órganos técnicos especializados e independientes de selección, evaluación, revisión y control, según fórmulas habituales en otros países, que en una regulación prolija de cautelas procedimentales ${ }^{18}$.

* El establecimiento de un régimen de incompatibilidades de los empleados públicos es, además de un mandato constitucional, una exigencia derivada de la naturaleza de la función desarrollada por aquéllos. Sin duda, la norma estatutaria debe incorporar en esta materia un conjunto de regulaciones destinadas a proteger valores específicos (primacía del interés público, imagen de la Administración), propios del ámbito público.

* Sería necesario establecer ciertas modulaciones específicas de los supuestos de suspensión de la relación de empleo contemplados por la norma laboral, que resultan parcialmente reconducibles a lo que en la esfera pública llamamos situaciones administrativas. Se trata, en todo caso, de una materia que, en buena parte, y sin perjuicio de un núcleo básico de regulación estatutaria, cabría desarrollar mediante negociación colectiva.

* Como antes se dijo, el contexto de no-mercado hará, en general dificultosa la constatación objetiva de la concurrencia de las causas económicas, técnicas, objetivas o de producción, que los arts. 41, 45, 47 y 51 del Estatuto de los Trabajadores (ET) contemplan como determinantes de la modificación sustancial de las condiciones de trabajo, la suspensión o la extinción de la relación de empleo, tanto en forma individual como colectiva.

La regulación estatutaria de esta materia deberá atender, por ello, a preservar la legitimidad de las decisiones que en este ámbito puedan adoptarse, mediante una regulación específica que perfile el alcance de los supuestos en los que tales causas puedan entenderse concurrentes, en el empleo público.

Asimismo, deberán precisarse los instrumentos necesarios para determinar válidamente tal concurrencia e identificar los puestos afectados. La reciente regulación de los planes de empleo representa un paso en esta dirección, susceptible, a mi entender, de mejora de su sistema de garantías, tanto en lo que respecta a su validez técnica como a su consistencia jurídica.

* Por lo que hace específicamente a los supuestos de suspensión o extinción colectiva de la relación, mi punto de vista es que el resto del procedimiento de regulación de empleo configurado por el ET podría ser sustancialmente aplicable al empleo público, salvo en lo que respecta al papel atribuído en el mismo a la autoridad laboral.

A mi juicio, la norma estatutaria debiera abordar la creación de una instancia independiente, provista de una consistente legitimidad técnica y dotada de un amplio consenso en cuanto a su configuración, ante la que deberían acreditarse tanto la concurrencia de las causas legalmente establecidas como la correcta identificación de los puestos afectados, y a quien habría de corresponder la resolución del procedimiento.

* La norma reguladora del empleo público deberá eliminar, tanto en la extinción por causas objetivas como en la de origen disciplinario, la facultad de sustituir la readmisión por indemnización, en el supuesto de improcedencia judicialmente declarada. Tal opción empresarial es incompatible a todas luces con el carácter de poder jurídico, predicable de las instituciones públicas.

* Parece imprescindible que la protección de valores específicos del ámbito público se plasme en la normación, por la vía estatutaria, del núcleo básico del régimen disciplinario de los empleados públicos. Este núcleo básico debiera comprender la tipificación de las infracciones, la graduación de las sanciones y los elementos esenciales del procedimiento.

Debe tenerse en cuenta, a estos efectos, que el régimen disciplinario se halla aquejado, como antes se dijo, en el marco jurídico vigente, de una rigidez que lo hace con frecuencia poco operativo. Por ello, la reforma legal debiera asumir en este campo una orientación que, sin perjuicio de las garantías esenciales, refuerce notablemente las posibilidades de efectiva corrección de comportamientos inadecuados o irregulares de los servidores públicos.

De otro lado, nada parece impedir que, fuera del indicado núcleo de derecho necesario, esta materia pueda ser objeto de desarrollo y adaptación a circunstancias específicas de los diferentes sectores de la acción pública, mediante la negociación colectiva ${ }^{19}$. 
* Las peculiaridades del ejercicio del derecho a la sindicación de los empleados públicos deben ser asimismo, por expreso mandato constitucional, objeto de regulación específica en la norma estatutaria.

* La negociación colectiva debiera ser objeto de un tratamiento específico, derivado de la existencia, en la esfera pública, de un núcleo de elementos de la relación de empleo cuya determinación es indisponible para las partes (sería el caso, por citar un ejemplo significativo, de las determinaciones sobre incrementos salariales globales, que competen al legislador y se incorporan a la norma presupuestaria). El nuevo estatuto deberá acotar con precisión el ámbito de fijación convencional de las condiciones de trabajo, y fijar las condiciones de ejercicio de la misma.

En lo que quede dentro de este ámbito, el reconocimiento del poder contractual de las partes debe ser inequívoco, superando el nominalismo con que actualmente se remiten a la negociación colectiva decisiones cuya efectividad depende de ulteriores actos de recepción normativa, o supuestos en los que la negociación deviene -por falta de instrumentos de resolución de discrepancias- un mero trámite formal previo a la adopción unilateral de decisiones por parte de la Administración actuante.

* Una configuración como la esbozada del régimen jurídico del empleo público parece postular de suyo una revisión trascendente del sistema de tutela jurisdiccional vigente. En concreto, parecería razonable atribuir a la jurisdicción laboral ordinaria la competencia para juzgar las cuestiones litigiosas que se susciten en el marco de la relación de empleo, entre las instituciones públicas y sus empleados.

Todo el ámbito de lo que el Derecho administrativo ha venido considerando relación de sujeción especial del servidor público respecto de la Administración ${ }^{20}$, sería reconducible a un marco relacional que no ofrecería diferencias sustantivas, a mi juicio, con el que la citada jurisdicción tiene atribuido como propio, tanto en la esfera privada como -no lo olvidemos- también en la pública: decenas de miles de relaciones de empleo entre Administraciones y empleados públicos no sujetos al estatuto son, desde hace décadas, objeto de efectiva tutela judicial por los tribunales laborales de nuestro país.

Ello no obstante, entiendo que deberá existir, en el marco del nuevo estatuto que se propugna, un ámbito de cuestiones litigiosas sustraído al conocimiento de la jurisdicción laboral. Me refiero a las cuestiones relativas al acceso a la función pública. Aquí, las resoluciones administrativas que se produzcan se configurarían como actos separables, situados fuera del marco de la relación de empleo o sujeción especial, a la que se ha hecho referencia. Tales actos afectarían a derechos e intereses de los ciudadanos frente a la Administración, constitucionalmente protegidos (art. 23.2 CE), cuya tutela habría de corresponder a los órganos judiciales que en nuestro ordenamiento la tienen atribuída, en lo que constituye el ámbito propio de la jurisdicción contencioso-administrativa.

\section{CONCLUSIÓN}

La reforma legal del empleo público, expectativa recurrente en nuestro mundo administrativo, vuelve al escenario. Su irrupción se produce en un contexto de cambios e incertidumbres que la hacen, al mismo tiempo, necesaria y difícil.

Ninguna reforma legal resolverá por sí misma los problemas que aquejan a nuestra función pública. El análisis de estos problemas y sus verdaderas causas es imprescindible para situar las reformas del marco jurídico en sus justos términos.

La obtención de una mejora significativa en los sistemas de gestión pública de los recursos humanos exige importantes transformaciones en el diseño organizativo de nuestras Administraciones, la definición y puesta en práctica de políticas innovadoras, y el desarrollo de estrategias de fortalecimiento interno de las organizaciones públicas. Sólo en este marco más amplio de renovación, la reforma legal cobra sentido.

La evolución de nuestra sociedad, y los nuevos desafíos que reclama de nuestro sistema público, exigen que la reforma no se limite a una revisión de elementos del marco jurídico que aparezcan especialmente desajustados. Son las bases mismas de nuestro modelo de empleo público las que se hallan puestas en cuestión.

Ello confiere a las reformas necesarias una dimensión subversiva. El empeño reformador debe objetar rasgos profundos de nuestra cultura administrativa, que forman parte del modelo. En particular, debe enfrentar una persistente tentación uniformadora, una tradición sesgadamente garantista, y un discurso asentado sobre la singularidad esencial del empleo público, concebido como un universo vertebrado sobre principios y bases conceptuales que lo configuran como radicalmente diferente del empleo común.

En este empeño, tan importantes son los contenidos de la reforma como el método seguido para abordarla. Sobre todo, porque aquéllos dependerán en gran medida de cuál sea la vía utilizada para definirlos. En este artículo, se ha defendido una orientación que toma como base o punto de partida la normación del trabajo por cuenta ajena en nuestra sociedad, incorporando a la misma las especialidades o derogaciones necesarias para la garantía de principios y valores propios de la esfera pública.

Un cabo queda suelto, y no es precisamente cuestión menor. El nuevo estatuto que se preconiza no resolvería por sí mismo uno de los problemas mencionados como carencia relevante de nuestro sistema público: el déficit de capacidad directiva. Abordar este serio problema exige una aproximación específica -jurídica y metajurídica- que escapaba al objeto de estas reflexiones. Quede, quizá, para otra ocasión.

Una apostilla final: la reforma del empleo público no es un problema de los funcionarios, sino de la sociedad en su conjunto. Mi opinión es que habría algo peor que mantener el marco vigente, y sería afrontar, una vez más, su reforma desde presupuestos y métodos que en el pasado han evidenciado reiteradamente sus limitaciones. La naturaleza de los cambios necesarios aconseja trascender la discusión entre expertos, transformándola en el amplio debate social que exigen cuestiones trascendentes para el presente y el futuro de nuestras Administraciones 
- Profesor del Instituto de Dirección y Gestión Pública de ESADE (Escuela Superior de Dirección y Administración de Empresas), en Barcelona. Ha sido director de recursos humanos y gerente de los servicios centrales del Ayuntamiento de Barcelona, y consejero de diversas empresas municipales. Fue director ejecutivo del Centro Municipal de Operaciones de los Juegos Olímpicos de 1992. Ha trabajado como consultor para el Instituto Europeo de Administración Pública, y para distintas instituciones públicas españolas. Es miembro del consejo de redacción de GAPP.

${ }^{1}$ Numerosas publicaciones han abordado en los últimos tiempos las transformaciones en el mundo del trabajo. Dos de ellas, muy breves ambas, me han parecido especialmente sugerentes: "Claves de la dinámica del mundo laboral de los 90", de Charles HANDY, en La dimensión bumana de la empresa del futuro, Deusto, 1992; y "The End of the Job", de William BRIDGES, en Fortune, septiembre 1994, pgs.46 y ss.

${ }^{2}$ Como se ha señalado al caracterizar las reformas británicas del empleo público, "...la finalidad fue asegurar que lo que una vez fue una gran burocracia homogénea fuera rediseñada para adaptarse a a las diferentes tareas, tecnologías y entornos que la función pública enfrenta en la última década del siglo XX". RICHARDS,S. y RODRIGUES J.: "Strategies for Management in the Civil Service: Change of Direction", en Public Money and Management, abriljunio 1993,pg.33.

3 V. PRATS J.: "Derecho y Management en las Administraciones Públicas", en Ekonomiaz, Revista Vasca de Economía, núm.26, 1993, pgs.131 y ss.

${ }^{4}$ Sobre la organización del sistema de GRH en la Administración federal norteamericana, v. NIGRO,L.G. y NIGRO,F.A.: "The new Public Personnel Administration", pgs. 40 y ss.(Civil Service Reform II:Making Government Work), F.E. Peacock Inc.,1994; y DRESSANG,D.L.: Public Personnel Management and Public Policy, pgs. 23 y ss. ("The Development of the Merit System"). Longman Publishing Group, N.Y.,1991.

5 BARZELAY, M.: "Metáforas en la gestión de servicios públicos". Gestión y Análisis de Políticas Públicas, núm 1, sept.-dic.1994.

${ }^{6}$ CASSESE,S.: Las bases del Derecho Administrativo, pg. 206. Ministerio para las Administraciones Públicas-INAP, Madrid,1994.

7 Un interesante análisis de la diversidad de vínculos laborales en un sector específico de nuestra Administración puede hallarse en JIMÉNEZ ROMANO,R: "El personal del Sistema Nacional de Salud. Una reflexión sobre su evolución, situación actual y perspectivas de futuro", en Revista de Sanidad e Higiene Pública, 1993,vol.67,núm. 5.

${ }^{8}$ Es de resaltar en especial el apartado cuarto del art. 15.1.c, de la Ley 30/84, que abre al empleo laboral "los puestos correspondientes a áreas de actividades que requieran conocimientos técnicos especializados, cuando no existan Cuerpos o Escalas de funcionarios cuyos miembros tengan la preparación específica para su desempeño". Lo que parece contar aquí no es la naturaleza de la función, ni su importancia, ni la necesidad de proteger especialmente tales o cuales valores, sino el hecho de que no se produzca lesión de intereses corporativos preexistentes. Para mayores precisisiones sobre el alcance de la delimitación, v. BERMEJO CABRERA, F.: "Las relaciones de puestos de trabajo y la laboralización de la Función Pública". REDA núm. 62, 1989.

9 Un empleado público escribía no hace mucho a un diario nacional lo siguiente; "Soy un contratado laboral en informática del Ministerio de Hacienda, y estoy hastiado y hasta el gorro de oír...afirmar que los contratados laborales de la Administración estamos en ella por enchufe o afiliación al partido del gobierno. Personalmente, para ingresar en el puesto en el que estoy trabajando, superé un concurso-oposición (exámenes, pruebas psicotécnicas, entrevistas) que se realizó en 1984. Sin pertenecer a partido alguno. Y ahora que quieren funcionarizar a los contratados laborales, el partido del gobierno hace realizar obligatoriamente otra oposición para el mismo puesto de trabajo y para desempeñar la misma labor que llevo realizando 11 años..." EL PAIS, 2 de febrero de 1995.

${ }^{10}$ La "funcionarización" no ha sido un fenómeno exclusivo de la Administración estatal, sino que ha afectado también a las comunidades autónomas (dando lugar incluso a leyes declaradas inconstitucionales), y a algunas administraciones locales. Un movimiento pendular de signo opuesto, que trae causa del Acuerdo Administración-Sindicatos, ha sido la apertura al empleo laboral de "los puestos con funciones auxiliares de carácter instrumental y apoyo administrativo", introducida por la reciente Ley 42/1994, de 30 de diciembre, de medidas fiscales, administrativas y de orden social (art. 59), que supone la consagración del criterio de regímenes distintos para idénticas funciones.

${ }^{11}$ Creo que debe valorarse positivamente que esta preocupación se halle presente en el Acuerdo Administración-Sindicatos para el periodo 1995-1997, sobre condiciones de trabajo en la Función Pública (cap. 22.2), cuando afirma "la conveniencia y oportunidad de estructurar un sector de personal directivo", si bien la referencia a una carrera directiva dentro de la función pública" podría abonar interpretaciones de signo endogámico que, personalmente, no compartiría.

${ }^{12}$ Diagnósticos en buena parte coincidentes pueden hallarse en el Informe de Resultados (pgs.19-39) del Estudio Delphi La modernización de los procedimientos de actuación en la Administración Pública, realizado por el MAP en 1990; y también, en el ámbito de una Administración autonómica, en el documento Una nueva organización para una nueva etapa del Gobierno Vasco. 47 medidas para renovar la estructura organizativa del gobierno y la Administración del País Vasco, pgs. 52,59,67 y 79. Gobierno Vasco, Instituto Vasco de Administración Pública, Vitoria-Gasteiz, julio 1994.

${ }^{13}$ LONGO,F.: "Diseño postburocrático de organizaciones públicas: La perspectiva divisional". Papers ESADE, núm.130, noviembre 1994.

${ }^{14}$ Una interesante descripción de cómo estas grandes reformas han afectado a la función pública puede encontrarse en el artículo del jefe del Civil Service britanico, Sir Robin BUTLER, "The Evolution of the Civil Service. A Progress Report", en Public Administration, vol.71, otoño 1993, pgs.395-406.

15 V. la Sentencia del Tribunal Constitucional núm 99/1987, de 11 de junio, dictada en el recurso de inconstitucionalidad 763/84; fundamento jurídico 3, ap. c). BOE de 26 de junio de 1987.

${ }^{16}$ Sigue pareciéndome modélico, en su simplicidad, el enunciado de los cuatro principios básicos del Civil Service británico: acceso abierto y transparente; promoción según el mérito; integridad, objetividad e imparcialidad; y no-politización. Sobre la permanencia de tales principios en el sistema actual de función pública en el Reino Unido, v. el estudio de la Unidad de Eficiencia del Cabinet Office, Career Management and Succession Planning Study. Londres,HMSO,1993.

${ }^{17}$ Sobre el alcance del concepto de flexibilidad para la OCDE, v. Flexibilitat $i$ Gestió de Personal a l'Administració Pública. OCDE. Escola d'Administració Pública de Catalunya, febrero 1992 :

${ }^{18}$ Toda esta materia ha sido objeto de un documentado y lúcido análisis en el estudio de Manuel FÉREZ La Igualdad, el Mérito y la Capacidad en el Acceso al Empleo Público Profesional (los casos de Estados Unidos, Francia y España), tesis doctoral pendiente de publicación.

19 Un reciente análisis de tal posibilidad es abordado por Joan PRATS, en "Régimen disciplinario laboral y funcionarial en las Administraciones públicas". Papers ESADE, núm 133, enero 1995.

${ }^{20} \mathrm{~V}$. GARCÍA MACHO, R.: Las relaciones de sujeción especial en la Constitución española Ed. Tecnos, 1992; y LÓPEZ BENÍTEZ, M.: Naturaleza y presupuestos constitucionales de las relaciones especiales de sujeción. Ed. Civitas, 1995. 
